\title{
A COMPETÊNCIA COMUNICATIVA NA PROVA DE REDAÇÃO DO CERTIFICATE OF PROFICIENCY IN ENGLISH (CPE) ESTUDO DE CASO
}

\author{
Célia Elisa Alves de Magalhães é professora de inglês como língua estrangeira (EFL) e aluna do curso de Mestrado em Estudos da \\ Linguagem na PUC-Rio. \\ E-mail: elisa.celiamagalhaes@gmail.com
}

\begin{abstract}
Resumo
Este artigo tem como objetivo avaliar o desempenho de um aluno de inglês como língua estrangeira na produção do gênero textual projeto, que faz parte da prova de redação do "Certificate of Proficiency in English" (CPE). Essa avaliação é feita com base nos aspectos linguísticos e convenções comunicativas relacionadas ao conceito de competência comunicativa descritas nos critérios de avaliação do Manual do CPE estabelecidos pelo Quadro Europeu Comum de Referência para Línguas, QECR. O artigo também discute a adequação dos critérios de avaliação propostos pelo referido Manual.
\end{abstract}

\begin{abstract}
The objective of this article is to analyze the performance of a student of English as a foreign language in the production of the textual genre 'proposal', which is part of the writing paper in the Certificate of Proficiency in English exam (CPE). This assessment is based on the linguistic aspects and communicative conventions related to the concept of communicative competence described in the assessment criteria found in the CPE Handbook and established by the Common European Framework of Reference for Languages (CEFR). The article also discusses the suitability of the assessment criteria proposed by the target Handbook.
\end{abstract}

\section{Introdução}

Existem diversos exames de avaliação de proficiência em língua inglesa como língua estrangeira, destacando-se entre eles o Certificate of Proficiency in English, designado pela sigla CPE, elaborado pela Universidade de Cambridge. O CPE atesta um nível altamente avançado de proficiência em língua inglesa em situações reais de comunicação para falantes não-nativos, nível C2 do Quadro Europeu Comum de Referência para Línguas, doravante QECR. O QECR é um guia usado para descrever os objetivos a serem alcançados pelos estudantes de línguas estrangeiras na Europa. Por isso, os aspectos avaliados no CPE assim como os critérios utilizados são baseados nesse referêncial teórico. Quanto ao termo "falante" não-nativo do nível C2, o mesmo refere-se ao candidato ao CPE, e não especificamente à habilidade oral desse candidato.

Segundo o manual do CPE (2008, p.2), os exames de Cambridge abrangem as quatro habilidades na língua: leitura, escrita, compreensão auditiva e fala; e avaliam, principalmente, a habilidade ou competência do candidato para comunicar-se eficientemente na língua inglesa. Consequentemente, é necessário para o candidato ao 
exame e para o professor que irá prepará-lo entender o significado dessa habilidade ou competência comunicativa.

O termo competência comunicativa tem-se constituído num dos mais controvertidos na Linguística (Hymes, 1992). Uma das razões para essa controvérsia é o fato de que a competência comunicativa não está limitada ao conhecimento estrutural da língua conforme o conceito de competência gramatical proposto por Chomsky (1965). Para Hymes (1972, apud Richards e Rodgers, 2004, p. 159), ao adquirir a competência comunicativa, o falante tem o conhecimento e a habilidade para usar a língua observando, por exemplo, se esse uso é adequado a determinado contexto, ou seja, a competência comunicativa também considera as dimensões sociais da língua refletidas na competência sociolinguística. $\mathrm{Na}$ prova de redação do $\mathrm{CPE}$, o conceito de competência comunicativa pode ser observado, de forma indireta, nos critérios de avaliação, pois estes priorizam os seguintes aspectos: o conteúdo do texto elaborado e o cumprimento da tarefa proposta, a coerência de ideias, o desenvolvimento do tema, e a variedade de itens léxico-gramaticais utilizados. A correção gramatical não é o aspecto mais importante para a obtenção da aprovação no referido exame.

Diferentes autores já pesquisaram o tema competência comunicativa em diversos contextos, incluindo as provas de proficiência escrita em língua materna e em segunda língua. Andrade \& Barreto (2009), por exemplo, analisaram o conceito de competência comunicativa a partir de sua definição no QERC, e as competências que se devem desenvolver nos alunos brasileiros do Ensino Médio nas disciplinas Língua Portuguesa e Línguas Estrangeiras Modernas, segundo os Parâmetros Curriculares Nacionais para o Ensino Médio (PCNEM).

Considerando o contexto de avaliação e do processo de ensino-aprendizagem em língua estrangeira, é importante ressaltar que o professor deve saber avaliar adequadamente as competências e habilidades que o aprendiz precisa desenvolver para comunicar-se eficientemente em diferentes situações e, consequentemente, prepará-lo de forma satisfatória seja para sua comunicação no dia-a-dia, seja para a sua aprovação em diferentes tipos de exames, como os exames de proficiência.

Diante desse quadro, o presente trabalho visa avaliar o desempenho de um aluno de inglês na prova de redação do CPE , considerando os aspectos linguísticos e as convenções relativas ao conceito de competência comunicativa na referida prova. A partir da análise dos dados, pretendemos responder às seguintes questões:

- Quais são os requisitos / aspectos comunicativos necessários para a obtenção da aprovação na Parte 2 da prova de redação do CPE? 
- O aluno em questão enquadra-se nas exigências do modelo de competência comunicativa propostas para a aprovação na parte 2 da prova de redação do CPE?

- Os critérios de correção da prova de redação do CPE são adequados para avaliar a competência comunicativa do candidato - teoricamente um falante do nível C2 segundo o QECR?

A relevância da pesquisa consiste em sua contribuição para a reflexão sobre o conceito de competência comunicativa na prova de redação do CPE e sobre os critérios de correção dessa prova. A partir do entendimento desses dois aspectos, é possível avaliar de forma mais eficiente a necessidade de um redirecionamento das práticas pedagógicas que visam levar os alunos de língua inglesa como língua estrangeira a um melhor desempenho e à consequente aprovação em exames de proficência na língua alvo.

São revistas na seção a seguir as premissas e pressupostos teóricos de diferentes autores (Chomsky, 1965; Hymes, 1967, 1972, 1992; Canale, 1983, 2001) visando a análise do conceito de competência comunicativa. O conceito de competência comunicativa proposto pelo QECR também é analisado brevemente. A seção subsequente trata da descrição da prova de redação do CPE e dos critérios gerais e específicos de avaliação dessa prova, com enfoque na Parte 2 da prova, parte analisada nesta pesquisa. $\mathrm{O}$ gênero textual escolhido, 'Projeto' ('Proposal'), também é definido segundo o Manual do CPE (2002). Na sequência, são fornecidas informações sobre a natureza da metodologia de pesquisa, sobre o participante da pesquisa, e sobre os procedimentos e critérios utilizados para a geração de dados. Na análise de dados, o desempenho do referido participante é avaliado a partir dos critérios gerais e específicos propostos por esse Manual, que utiliza os aspectos linguísticos e convenções comunicativas relacionadas ao conceito de competência comunicativa descrito pelo QECR. Ainda considerando o conceito de competência comunicativa, discute-se a adequação dos critérios de avaliação para a referida prova propostos pelo Manual do CPE. Na conclusão, são retomados os resultados da análise para a elaboração das considerações finais e de proposta de procedimentos futuros para a continuidade desta pesquisa.

\section{1) O Conceito de competência comunicativa}

Segundo Celce-Murcia e Olshtain (2000, p.16), o conceito de competência comunicativa foi criado por Hymes (1967 \& 1972) e seus colegas de diferentes áreas da linguística (antropológica, sociológica e funcional), que argumentavam que a competência linguística consistia não só da competência gramatical de Chomsky (1965), mas também da competência sociolinguística ou pragmática. Na obra The concept of communicative competence revisited, Hymes (1992, p. 31-57) analisa uma série de termos e ampliações do 
conceito feitas por diversos autores e concebe a competência comunicativa como uma combinação de competências que ultrapassam o conhecimento gramatical e atingem situações de uso da língua, englobando aspectos sociolinguísticos e pragmáticos, entre outros, como o conceito de comunidade de fala, identidade e pertencimento.

Canale (1983, p. 2-14) também busca definir o termo competência comunicativa, e cria um enquadre teórico, modelo que se destaca na área de avaliação de ensino e aprendizagem de línguas. Para Canale (1983), os alunos adquiririam competência comunicativa se ficassem expostos a quatro formas de competência: a competência gramatical, a competência sociolinguística, a competência discursiva e a competência estratégica.

A competência gramatical relaciona-se ao domínio das regras fonológicas e léxicogramaticais de formação de uma sentença; isto é, à capacidade do falante em interpretar o sentido de uma sentença através de seu conhecimento da pronúncia, vocabulário, sentido e formação das palavras e sentenças, e soletração correta na língua alvo. A competência sociolinguística refere-se às regras socioculturais do uso da língua; ou seja, ao conhecimento e à habilidade que o falante possui para expressar e entender enunciados de um modo apropriado, de acordo com fatores sociais e culturais do contexto em que se encontra, tais como os propósitos e as normas da interação e o tipo de relação que o falante possui com o interlocutor. Já a competência discursiva aborda o domínio das regras que regem a coesão e a coerência do discurso na língua. Nesse sentido, um texto alcança unidade por meio da coesão de sua forma e da coerência de seu significado. A competência estratégica diz respeito ao domínio da estratégia comunicativa na comunicação verbal e não verbal no uso da língua para compensar deficiências na competência gramatical e sociolinguística. Esse objetivo pode ser alcançado através da paráfrase, ou através da fala mais lenta com o objetivo de alcançar um efeito retórico, por exemplo.

O conceito de competência comunicativa proposto pelo QECR, assemelha-se ao modelo de competência comunicativa proposto por Canale (1983). De acordo com o QECR (2001, p. 34-35), a competência comunicativa compreende diferentes componentes: a competência linguística, a sociolinguística e a pragmática.

A competência linguística abrange conhecimentos lexicais, fonológicos, sintáticos, ortográficos, e elementos da constituição do texto como coesão e coerência (Oliveira, 2008, p. 195-200). É importante ressaltar que diferentes autores sugerem diferentes formas para categorizar a propriedade de coesão, ou seja, para categorizar "o conjunto de estratégias de sequencialização responsável pelas ligações linguísticas relevantes entre os constituintes articulados no texto" (Oliveira, 2008, p. 195). Segundo Halliday e Hasan (1976, apud Oliveira, 2008, p. 195-200), por exemplo, são cinco os mecanismos de coesão: referênca (endofórica e exofórica), substituição, elisão, conjunção e coesão lexical. 
A referência constitui-se na relação dos elementos textuais com outros elementos presentes no texto ou não. Quando esta relação se processa no nível situacional ou extralinguístico é denominada exofórica. Quando ocorre nos limites do texto é denominada endofórica. As referências endofóricas se subdividem em anáforas, que se referem aos elementos anteriores; e catáforas, que se articulam numa conexão com os elementos posteriores. A substituição consiste em uma remissão coesiva em que o termo substituído não recupera totalmente o item ao qual se refere; ou seja, embora se aproximem em termos semânticos, não possuem equivalência absoluta de sentido. A elisão se trata de um mecanismo de omissão de um constituinte recuperável pelo contexto, a partir das informações que ocorreram num momento anterior. A conjunção caracteriza-se pelo estabelecimento de ligações lógico-semânticas na sequencialização textual, como temporalidade e consequência. Finalmente, a coesão lexical envolve a repetição do mesmo elemento lexical ao longo do texto ou a sua substituição por outras unidades lexicais que com ela mantêm relações semânticas de natureza hierárquica (hiponímia, hiperonímia) de inclusão (holonímia, meronímia) ou não hierárquica (sinonímia, antonímia).

A coerência, propriedade relativa à construção do sentido textual, de acordo com Oliveira (2008, p. 201), abrange três domínios: linguístico, pragmático e extralinguístico. O domínio linguístico relaciona-se aos recursos léxico-gramaticais, fonético-fonológicos, semânticos e morfossintáticos. O domínio pragmático refere-se às condições de realização da interação; isto é, relaciona-se aos aspectos envolvidos no ato comunicativo em que o texto é produzido e recebido: contexto situacional, tipo de fala, intenção e aceitação comunicativas, valores e crenças dos participantes da interação e demais aspectos que interferem na produção de sentido textual. O domínio extralinguístico diz respeito ao conhecimento de mundo, aos conteúdos e informações necessários para a elaboração linguística e (de)codificação do texto, às vivências e experiências dos participantes da situação comunicativa.

Por sua vez, a competência sociolinguística, segundo Canale (1983), refere-se ao significado e à forma da fala em diferentes contextos sociolinguísticos, dependendo de fatores contextuais como o papel dos participantes, os propósitos da interação e as normas e convenções da situação comunicativa.

Finalmente, de acordo com Yule (1996, p. 3), a pragmática é a área que lida com o estudo do significado comunicado pelo falante (ou escritor) e interpretado pelo ouvinte (ou leitor). Nesse sentido, a pragmática relaciona-se mais estritamente com a análise do que as pessoas querem dizer do que necessariamente com aquilo que as palavras ou frases produzidas possam significar por si só: "Pragmatics is the study of speaker meaning". (Yule, 1996, p. 3). Sendo assim, a competência pragmática pode ser definida como "um conjunto de regras internalizadas de como usar a língua de maneiras socioculturalmente 
apropriadas, levando em consideração os participantes na comunicação interativa e as características do contexto dentro do qual a interação acontece" (Celce e Murcia, 2000, p. 19).

Para atender às especificações referentes ao conceito de competência comunicativa proposto pelo QECR, a prova de redação do CPE deve contemplar esses três componentes em seus critérios de correção: a competência linguística, a sociolinguística e a pragmática. A seguir, a prova de redação do CPE e os seus critérios de correção são descritos.

\section{2) A prova de redação do CPE e os critérios de correção}

De acordo com o Manual do CPE (2008, p. 18-19), a prova de redação do CPE encontra-se dividida em duas partes: Parte 1 e Parte 2, e tem a duração de 2 horas. Cada parte constitui-se de uma tarefa a ser cumprida, isto é, de um texto a ser elaborado, em 300 a 350 palavras. Enquanto a parte 1 é composta de uma única tarefa obrigatória; na parte 2, o candidato deve escolher uma tarefa dentre cinco opções oferecidas. Na Parte 1, o candidato deve elaborar seu texto após a leitura das instruções que são compostas de um texto (partes de jornais, revistas, etc.) de 100 palavras. O foco da tarefa é discursivo. Na Parte 2, as instruções são compostas de textos de 70 palavras. As tarefas referem-se à elaboração dos seguintes gêneros textuais: um artigo, ensaio, carta ou projeto ('proposal') na Parte 1; e um artigo, carta, ensaio, projeto ('proposal'), relatório ou resenha (de filme, livro, hotel, etc.) na Parte 2.

\section{1) Os critérios gerais de correção da prova de redação do CPE}

Segundo o Manual do CPE para professores (2008, p. 25-26), a avaliação da prova de redação do CPE é baseada em dois critérios de correção. Um deles compreende a impressão geral do examinador em relação ao conteúdo, à organização e coesão do texto, à variedade de itens lexicais e gramaticais, ao registro e formato do texto, e ao leitor indicado na tarefa. $\mathrm{O}$ outro critério baseia-se em parâmetros específicos relativos ao conteúdo do texto para o cumprimento da tarefa. Os examinadores utilizam os dois critérios de correção para fazer comentários sobre os diferentes aspectos da prova e para atribuir uma nota final que varia em uma escala de 0 a 5.

As notas atribuídas para o uso correto da língua, da ortografia e da pontuação seguem os critérios gerais de correção. No entanto, embora os candidatos possam perder pontos por inclusão de conteúdo irrelevante à tarefa, por exemplo, a prioridade do examinador é dar crédito aos esforços dos candidatos para se comunicarem. 
Para a avaliação, também é importante que o examinador saiba a definição de um falante da língua no nível de CPE. De acordo com o QECR, para a aprovação na prova do $\mathrm{CPE}$, nível C2, o falante deve ser proficiente na língua inglesa. Essa classificação significa que esse falante:

É capaz de compreender, sem esforço, praticamente tudo o que ouve ou lê. É capaz de resumir as informações recolhidas em diversas fontes orais e escritas, reconstruindo argumentos e factos de um modo coerente. É capaz de se exprimir espontaneamente, de modo fluente e com exactidão, sendo capaz de distinguir finas variações de significado em situações complexas. (QECR, 2001:49)

\section{2) O gênero textual projeto e os critérios específicos de correção}

Utilizamos uma prova de CPE (2002, p. 33), na qual, uma das tarefas a ser escolhida na uma das tarefas a ser escolhida na Parte 2 da prova de redação era a elaboração do gênero textual projeto. Resumidamente, para a elaboração desse texto, o candidato deveria imaginar-se pesquisador de uma agência de turismo e criar um projeto para o seu gerente, objetivando atrair mais turistas locais e estrangeiros para a sua cidade. Esse projeto deveria incluir ideias para melhorar as comodidades urbanas e aumentar a renda proveniente do turismo local.

De acordo com esse manual (2002, p. 36), na correção do texto, os examinadores devem considerar aspectos relativos ao conteúdo (sugestões para atrair mais visitantes para a cidade, para melhorar as comodidades urbanas, e para aumentar a renda relativa ao turismo na região), à variedade de estruturas léxico-gramaticais utilizadas (linguagem para descrever, analisar, fazer recomendações e talvez formular hipóteses), ao registro (variedades linguísticas relacionadas ao nível de formalidade, ou seja, o registro adequado para a relação de negócios entre pesquisador e gerente do escritório) e formato do texto (formato do gênero projeto com organização do texto em seções com títulos), à organização e coesão (texto bem estruturado escrito em prosa, dividido em seções, e desenvolvido em parágrafos de forma coesa), e ao leitor, ou seja, o gerente, que deve entender claramente o projeto apresentado.

Em anexo encontra-se uma cópia da versão em português (tradução feita pela autora deste artigo) dos seguintes textos: a tabela com os critérios gerais de correção da Parte 1 e 2 da prova de redação do CPE (Anexo 1), as instruções da Parte 2 da prova de redação do CPE para a elaboração do gênero textual projeto e os critérios de correção específicos dessa parte (Anexo 2), uma redação (para modelo/padrão de correção) avaliada pelo grupo de examinadores de provas escritas da Universidade de Cambridge (Anexo 3), e o texto elaborado pelo participante da presente pesquisa (Anexo 4). Esse texto foi analisado 
conforme as instruções do manual do CPE (2002, p. 30-36), o qual estabelece que as redações sejam avaliadas com base nos critérios gerais encontrados na tabela de correção de redação do CPE e nos critérios específicos às tarefas da Parte 2.

\section{3) Metodologia de pesquisa}

A abordagem da pesquisa sociolinguística que norteia este trabalho insere-se na tradição de pesquisas qualitativas e, mais especificamente, no paradigma interpretativista (Alwritght e Balley, 1991 e Lincoln e Guba, 2006). Na pesquisa qualitativa, diferentemente da quantitativa, "há aceitação explícita da influência de crenças e valores sobre a teoria, sobre a escolha de tópicos de pesquisa, sobre o método e sobre a interpretação de resultados” (Günther, 2006, p. 203).

A metodologia da pesquisa insere-se no âmbito da pesquisa etnográfica (André, 2008). Para André (2008), o estudo do tipo etnográfico deve apresentar características tais como: a) uso de técnicas associadas à observação do participante, à entrevista intensiva, e à análise de documentos; b) pesquisador como instrumento principal na geração e na análise dos dados, c) ênfase no processo e não nos resultados, d) preocupação com o significado atribuído pelos participantes da pesquisa às suas ações. O modo de pesquisa adotado é o estudo de caso. Uma das características do estudo de caso é a ênfase em compreender o que está acontecendo a partir da perspectiva do participante ou dos participantes da pesquisa, sendo este tipo de estudo indicado, entre outras situações, quando ele é extremo ou único (Yin, 1999).

O participante da pesquisa, cuja língua materna é o português do Brasil, é médico e professor universitário com experiência em escrever artigos científicos em português e em inglês na sua área de atuação, além de ser palestrante em congressos e seminários. Seus estudos na língua inglesa iniciaram-se na adolescência e desenvolvem-se até hoje, pois o participante considera o ato de estudar inglês uma experiência prazerosa. Ele também relatou ter planos de dar aulas de inglês. Por isso o certificado do CPE seria importante em seu processo de formação como professor de língua inglesa.

O participante foi meu aluno de inglês durante alguns meses, período durante o qual expressou o desejo de prestar o exame de CPE. A partir de observações e avaliações informais feitas em sala de aula (e com base na minha experiência como examinadora da prova oral do CPE e como professora de curso preparatório para o referido exame), percebi que o aluno precisaria desenvolver suas habilidades orais e escritas para alcançar sua aprovação no CPE. Entretanto, através de uma conversa informal, foi possível diagnosticar a prioridade do aluno, que era relativa ao desenvolvimento de suas habilidades na escrita. Consequentemente, devido à prioridade do aluno ser o desenvolvimento da sua produção 
textual e ao fato do presente trabalho ser uma análise inicial do desempenho desse aluno, foram gerados dados referentes somente à Parte 2 da prova de redação do CPE. Não foram gerados dados para a análise da Parte 1, pois o grau de dificuldade dessa parte é maior por envolver a compreensão e utilização de instruções mais longas (input para a tarefa). Essa parte da prova será foco de pesquisa posterior, não integrante deste trabalho.

As tarefas da Parte 2 da prova de redação do CPE referem-se à elaboração dos seguintes gêneros textuais: artigo, carta, ensaio, projeto ('proposal'), relatório ou resenha (de filme, livro, hote, etc.). Após a referida conversa informal com o aluno, resolvemos (pesquisador e pesquisado) começar a pesquisa através de um gênero que ele considerasse mais difícil. O gênero escolhido pelo aluno foi o gênero textual projeto ('proposal'). Segundo o manual do CPE (2008, p. 21), o gênero projeto tem um formato similar ao gênero relatório. No entanto, enquanto o relatório é um relato de algo que já aconteceu, o foco do gênero projeto encontra-se no futuro e o objetivo principal é fazer recomendações para discussão.

Na geração dos dados para a Parte 2 da prova de redação do CPE, o aluno recebeu o referido material de prova (Item 2 da Parte 2 do Manual do CPE de 2002, Anexo 1), e foi pedido a ele que escrevesse em sua casa o gênero textual escolhido e que ele anotasse o tempo gasto na sua elaboração, lembrando-se que ele deveria levar menos de uma hora na produção desse texto. Os dados assim gerados são analisados na seção seguinte.

\section{5) Análise de dados e o gênero textual projeto}

O QECR (2001, p. 34-35) afirma que a competência comunicativa compreende a competência linguística, a sociolinguística, e a pragmática. Consequentemente, para atender às especificações do QECR, a prova de redação do CPE deve contemplar esses três componentes não só na elaboração das tarefas comunicativas a serem cumpridas pelo candidato, mas também em seus critérios de correção. Por isso, a tabela de critérios gerais de correção da prova de redação abrange os seguintes itens: pontuação, ortografia e correção / acuidade da língua, organização, coerência e desenvolvimento do tópico, e efeito causado no leitor. De forma similar, os critérios de correção específicos das tarefas da prova de redação consideram os seguintes aspectos: conteúdo e efeito no leitor, variedade de estruturas lexico-gramaticais, formato do texto e registro, e organização textual e coesão. A pontuação, a ortografia e a correção da língua são consideradas na tabela relativa aos critérios gerais de correção. A seguir, o gênero textual projeto produzido pelo participante da pesquisa é analisado em diferentes subseções com base nesses critérios. Vejamos primeiramente, no entanto, o texto completo na versão original para melhor compreensão da análise oferecida (em anexo encontra-se uma cópia da versão em português). 
How to attract more tourists

$1 \quad$ Introduction

2 Rio de Janeiro is a wonderful city with beautiful beaches and a warm weather. Besides the seaside

we

3have even at least two cities (Petrópolis and Teresópolis) in the mountain, almost $1000 \mathrm{~m}$ above the sea level 4with a not so hot weather.

5 Having all these favourable characteristics we prepared this proposal with the aim of attracting more 6tourists to our region.

$7 \quad$ Data collection

8 We need some data about the thourists to plan the proposal. So, we made a population survey 9including the thourists who arrive by plane and by boat to the town. Three hundred tourists were randomly 10choosen to give an interview and declare their expectations during this tour. They said that they would like 11to travel with security, have good accommodations and well prepared local guides to local events. They 12would like also to taste local food and see shows of popular music. Another information they would like was 13 to be informed about the consulates of their country, considering Rio de Janeiro is a very big and important 14city in Brazil and should have all these facilities.

15 The proposal

16 Considering the problems identified in the survey we propose some procedures. The first one is to 17contact the local police to prepare a plan with special attention to the thourists as soon they arrive. This 18means a group of policeman talking different languages, mainly English, to give support to any need (this 19could be called The Thourist Police). The second point was accommodation, which must be provided by the 20best hotels in the town, integrated in a system of high quality assistance. This could include a reception show 21at their arrival what could demonstrate our sympathy for them. After the arrival the hotels, as a whole, 22should provided transport, so that they could have facilities in this moment and didn't depend on the public 23transportation system, which we know, is deficient. At the moment of the transportation to the hotels they $\mathbf{2 4}$ would know the specialized local guides. They could receive a brochure, specially made for them, telling the 25main events in town during the month, including shows of popular music.

26 In conclusion we think this proposal will attract more thourists to this town considering it was made in 27 according to the thourits expectancies.

\section{1) Conteúdo e efeito no leitor}

Conforme as instruções para a elaboração da proposta, o texto deveria contemplar três aspectos: o aumento do número de turistas locais e estrangeiros na cidade em questão, a melhoria das comodidades urbanas da região, e o aumento da renda proveniente do turismo local. No texto produzido há evidências de foco na ideia de atrair mais turistas e de melhorar as comodidades urbanas nos seguintes trechos: ... viajar com segurança, ter boas acomodações e guias bem preparados... (linha 11)... fornecer transporte... (linha 22),... receber o panfleto... (linha 24). Também há referência à presença de turistas estrangeiros: ... consulados dos seus países... (linha 13).

$\mathrm{O}$ texto também menciona uma pesquisa feita sobre as expectativas dos turistas (linhas 8-14). No entanto, este relato sobre uma pesquisa já feita é característico do gênero 
relatório, e não do gênero projeto. De acordo com o Manual do CPE (2008, p. 21), o foco do gênero relatório encontra-se em resultados, em relatos de algo que já aconteceu; enquanto que no gênero projeto, o foco encontra-se no futuro e o objetivo principal é fazer recomendações para uma discussão. Por outro lado, não há referência explícita ao aumento da renda proveniente do turismo.

De forma geral, o tema é razoavelmente desenvolvido e o leitor é parcialmente informado sobre os itens solicitados na pesquisa.

\section{2) Variedade de estruturas lexicais e gramaticais}

$\mathrm{Na}$ categoria de variedade de estruturas para o gênero projeto, espera-se que sejam usados itens léxico-gramaticais que sinalizem descrição, análise e formulação de hipóteses. No texto produzido, observa-se uma tentativa, embora limitada para o nível de proficiência em questão, de utilização da linguagem alvo. De fato, o aluno descreve a cidade do Rio de Janeiro como uma cidade maravilhosa com lindas praias e clima quente (linha 2), e apresenta Petrópolis e Teresópolis, que estão quase 1000 m acima do nível do mar (linha 3); analisa alguns problemas: Precisamos de algumas informações sobre os turistas para planejar... (Linha 8); e sugere soluções: O primeiro é contatar a policia local para.... (linha 17), ... O segundo foi a acomodação que deve ser fornecida ... (linha 19). Também há uma tentativa de formulação de hipótese: Considerando o problema identificado na pesquisa propomos alguns procedimentos... (linha 16).

No nível do CPE, espera-se que o candidato utilize um maior número de estruturas complexas como orações subordinadas condicionais e marcadores discursivos (aditivos, de causalidade, etc.) para a estruturação do texto. Em geral, o desempenho do candidato é limitado.

\section{3) Formato do texto e registro}

Em relação ao formato do texto, observa-se que as ideias são organizadas e apresentadas em parágrafos com a divisão dos assuntos no texto em sessões com títulos. O aluno também apresenta sua proposta no parágrafo de introdução e sugere algumas ações para alcançar seu objetivo na seção intitulada "O Projeto" (linhas 15). Todavia, não há uma seção intitulada "Conclusão", há somente um parágrafo que se inicia com um marcador discursivo que sinaliza conclusão (linha 26).

Quanto ao registro linguístico utilizado, há uma tentativa de apresentar a proposta de uma maneira mais formal através do uso de fatos, por exemplo, e não somente de opiniões; através da organização do texto em seções com títulos, e de linguagem adequada 
para a relação de negócios entre pesquisador e gerente da agência de turismo: Precisamos de algumas informações sobre os turistas para planejar a proposta. (linha 8), Tendo todas essas características favoráveis... (linha 5).

Nesta categoria, o desempenho do candidato é satisfatório.

\section{4) Organização textual e coesão}

A organização textual abrange a organização temática, a sequenciação de idéias, e a coesão e coerência textual. No que diz respeito à organização textual, observa-se a progressão temática e o encadeamento das partes do texto. Entretanto, embora o texto esteja dividido em parágrafos, o parágrafo de introdução encontra-se fragmentado em duas frases que poderiam estar unidas no mesmo parágrafo. A conclusão também poderia resumir as sugestões oferecidas no corpo do texto.

Segundo Fávero (2010, p. 61), a coesão fornece a estruturação da sequência do texto; enquanto que a coerência caracteriza-se como o nível de conexão conceitual e estruturação do sentido. Diferentes autores propõem diferentes classificações para os mecanismos de coesão e coerência. No texto produzido, verificamos diferentes tipos de mecanismos de coesão. Há exemplos de coesão por reiteração lexical: turistas (linhas 6) e os turistas (linha 8); referencial por substituição: turistas (linha 9) e eles (linha 10); uso de operadores discursivos: então (linha 8), de maneira que (linha 22); sequenciação temporal: depois (21); elipse: Considerando os problemas identificados na pesquisa nós propomos... (linha 16); entre outros. No entanto, o aluno poderia ter usado um maior número de orações e conjunções subordinadas, que são marcadores de um nível mais elevado de proficiência na língua inglesa. Além disso, ele utiliza diferentes tempos verbais (presente do indicativo: é, e pretérito perfeito: foi) e diferentes estruturas sintáticas (verbo no infinitivo: constatar e substantivo: acomodação) nas frases que enumeram os procedimentos propostos no parágrafo "O projeto" (linhas 16 a 20), afetando a sequenciação temporal e o paralelismo das frases: $O$ primeiro é contatar a polícia local para... (linha 16), O segundo ponto foi a acomodação, que deve ser fornecida... (linha 19).

De forma geral, observa-se que o texto apresenta uma organização relativamente clara e que é geralmente coerente devido à coesão satisfatória apresentada e ao seu esquema textual, conceito desenvolvido por Van Dijk e que se caracteriza como a forma global de um texto, que define sua organização e as relações hierárquicas entre seus fragmentos (Van Dijk, 1977 apud Fávero, 2010, p. 71).

O texto ultrapassou o número de palavras determinadas pelos organizadores da prova, totalizado 370 palavras ao invés de estar entre 300 e 350, mas foi elaborado dentro 
do limite de tempo solicitado (menos de 1 hora). De forma geral, o texto está organizado de maneira satisfatoriamente clara e coerente, embora limitada.

\section{5) Pontuação, ortografia e acuidade da língua}

No que diz respeito aos erros relativos à pontuação, ortografia e acuidade da língua observa-se que os erros cometidos pelo participante da pesquisa não chegam a interferir na compreensão do texto.

Há alguns erros de pontuação com a supressão da vírgula: Além da costa nós... ao invés de Além da costa, nós... (linha 2), Considerando os problemas identificados na pesquisa nós propomos... ao invés de Considerando os problemas identificados na pesquisa, nós propomos... (linha 16). É possível observar também alguns erros de ortografia: thourists ao invés de tourists para se referir aos turistas (linha 9, 10). Quanto à acuidade da língua, observa-se o uso correto de tempos verbais e de pronomes relativos: que, quem (linha 9, 10). Em relação ao vocabulário, o aluno faz uso de palavras específicas para o tema: acomodações (linha 11), guias (linha 11), panfletos (linha 24), etc. Por outro lado, observa-se a escolha incorreta de algumas palavras (linha 21): sympathy (solidariedade) ao invés de hospitality (hospitalidade). Encontram-se ainda, erros relativos aos substantivos contáveis e não contáveis em inglês: um clima quente (linha 2), por exemplo, em inglês, o substantivo clima (weather) não é precedido de artigo indefinido. Há também um erro relativo ao sujeito da frase em: Tendo todas essas características nós preparamos... (linha 5). O sujeito da oração Tendo todas essas características é o Rio de Janeiro, e não o sujeito nós. Outros erros relativos à correção da língua encontram-se no texto como, por exemplo, a ordem de elementos na frase: ... would like also to taste... (... também gostaria de experimentar...) ao invés de would also like to taste... (linha 12), uso incorreto do pronome relativo what (que), que se refere à oração precedente ao invés de which (que), que se refere à oração subsequente (linha 21).

Nesta categoria, o desempenho do candidato, encontra-se entre satisfatório e inadequado para o nível de proficiência esperado.

\section{6) Discussão}

Considerando o conceito de competência comunicativa, fazemos a seguir algumas considerações a respeito da adequação dos critérios de avaliação para a Parte 2 da prova de redação do exame $\mathrm{CPE}$. 


\section{1) Quais são os requisitos / aspectos comunicativos necessários para a obtenção da aprovação na Parte 2 da prova de redação do CPE?}

Para a obtenção da aprovação na prova de redação do CPE, os candidatos têm seus textos avaliados de acordo com os critérios de avaliação específicos e gerais estabelecidos pelos elaboradores das questões de redação do CPE. Esses critérios são formulados obedecendo ao conceito de competência comunicativa proposto pelo QECR e o candidato deve ser capaz de atender a esses requisitos satisfatoriamente para ser aprovado

Como vimos na seção 2 do presente trabalho, o conceito de competência comunicativa, segundo o QECR (2001, p. 34 - 35), compreende três componentes: a competência linguística, a sociolinguística e a pragmática. A competência linguística abrange os conhecimentos lexicais, fonológicos, sintáticos, ortográficos, e elementos da linguística textual como coesão e coerência; a competência sociolinguística diz respeito às condições socioculturais do uso da língua; e a competência pragmática relaciona-se ao significado comunicado pelo falante (ou escritor) e interpretado pelo ouvinte (ou leitor). É possível inferirmos o fato de que as definições relativas às competências sociolinguística e pragmática se sobrepõem em determinados aspectos. Por exemplo, ambas consideram fatores contextuais como os participantes e aspectos da interação. No entanto, na avaliação do desempenho do candidato à prova não é necessário enquadrar as partes do texto produzido segundo as três competências integrantes do termo mais amplo classificado como competência comunicativa. Os critérios de correção avaliam aspectos mais específicos (coesão, coerência, efeito no leitor, etc.) que são parte de cada uma dessas competências e que tornam a avaliação mais clara e objetiva para o examinador e para o candidato avaliado.

\section{2) O candidato em questão enquadra-se nas exigências do modelo de competência comunicativa proposto para a aprovação na parte 2 da prova de redação do CPE?}

As considerações feitas nesta seção sobre o gênero textual projeto produzido pelo participante desta pesquisa apontam para uma nota final próxima de 3.0, o que indica um desempenho próximo de satisfatório na Parte 2 da prova de redação do CPE. Conclui-se então que o texto elaborado poderia receber a nota mínima para a aprovação nesta parte da prova de redação do CPE. Entretanto, seria necessário investigar o desempenho do candidato nos outros gêneros discursivos da Parte 2 e da Parte 1 para uma melhor avaliação das suas condições de aprovação em ambas as partes da prova de redação do CPE, e também para um direcionamento mais eficiente na sua preparação para o exame. 


\section{3) Os critérios de correção da prova de redação do CPE são adequados para avaliar a competência comunicativa do candidato - teoricamente um falante do nível C2 segundo o QECR?}

Em algumas provas e testes, a correção gramatical é um dos fatores mais importantes para avaliar a qualidade de um texto escrito. Em outros tipos de testes e provas, o conteúdo é o principal elemento a ser considerado. Sem dúvida, o estabelecimento de parâmetros adequados para aferir a qualidade de um texto pode ser uma questão polêmica.

Os critérios de avaliação específicos e gerais da prova de redação do CPE buscam abranger diferentes aspectos relativos à competência comunicativa na produção de um texto escrito. Por isso, na avaliação da redação, são considerados tanto os aspectos associados à competência lingüística (como a correção e diversidade léxico-gramaticais, coesão e coerência) quanto os fatores referentes a aspectos sociolinguísticos e pragmáticos (como o contexto situacional, o propósito da comunicação, e os participantes desse contexto, escritor e leitor). Esses critérios parecem ser adequados no sentido de aferir a competência comunicativa dos candidatos na prova de redação do CPE.

Por outro lado, podem surgir dúvidas no que tange ao nível de proficiência do candidato, ou seja, no que diz respeito ao nível de competência comunicativa esperado para um falante C2. Embora o QECR forneça uma definição para o falante de nível C2, a definição por si só não é totalmente esclarecedora. É possível que o examinador (ou professor que prepara o aluno para a prova) possa ter dúvidas em atribuir uma nota final para as redações, principalmente no caso das redações que estejam entre as notas 4 (nível bom) e 5 (nível excelente). Para facilitar a avaliação dessas redações, é importante que os examinadores (e professores que ministram cursos preparatórios) familiarizem-se com o sistema de correção estabelecido pela instituição que elabora as provas, a Universidade de Cambridge, através da leitura e análise de avaliações feitas pela referida instituição. Essas amostras de avaliação (correção de provas de candidatos ao exame de CPE) são fornecidas no Manual do CPE disponível na internet. Além disso, é essencial que examinadores e professores entendam exatamente o que significa ser um falante de nível C2 e o que, consequentemente, é esperado desse falante na prova do CPE.

O falante do nível C2 é o falante de nível mais proficiente na escala de proficiência do QECR e o CPE é a prova mais complexa dentre as provas de Cambridge. Falantes menos proficientes na língua encontram-se em outros níveis de proficiência segundo o QECR e podem prestar outros exames de proficiência oferecidos pela Universidade de Cambridge e por outras instituições. 


\section{Considerações finais}

A análise do gênero textual projeto produzido pelo participante desta pesquisa mostra que no referido texto transparecem noções de aspectos linguísticos e convenções comunicativas relacionadas ao conceito de competência comunicativa descrita pelo QERC e presentes na prova de redação do CPE: competência linguística, sociolinguística e pragmática. Todavia, em diferentes momentos, as convenções utilizadas pelo participante da pesquisa não se encontram em nível de conformidade totalmente satisfatório com o nível de proficiência do CPE, nível C2 de acordo com o QERC. No entanto, o texto elaborado poderia receber a nota mínima para a aprovação na Parte 2 da prova de redação do CPE. Quanto à adequação dos critérios de avaliação para aferir a competência comunicativa na prova de redação do $\mathrm{CPE}$, vimos que esses critérios são adequados porque abrangem diferentes aspectos da competência comunicativa (competência linguística, sociolinguística e pragmática), e avaliam o candidato dentro do nível de proficiência esperado para um falante de Nível C2 no QECR. Por outro lado, constatamos que pode haver dúvidas quanto à avaliação e atribuição de notas se o examinador não estiver familiarizado com o sistema de correção da referida prova e/ ou com o que deve ser esperado de um falante de nível C2 em termos de competência comunicativa.

Sabemos que a presente pesquisa não fornece um parecer definitivo em relação ao futuro desempenho do participante desta pesquisa na prova de redação do CPE (Parte 1 e 2 do exame), ou seja, a partir de um único texto gerado por ele não é possível avaliar se ele apresentaria os aspectos linguísticos e convenções comunicativas exigidas para a sua aprovação na referida prova. Seria necessário analisar seu desempenho na produção de outros gêneros textuais que integram a Parte 2 da prova, assim como aqueles que integram a Parte 1. Contudo, esperamos que esta análise possa contribuir, ainda que modestamente, para que seja possível traçar um direcionamento eficiente na avaliação e preparação deste aluno ao exame do CPE.

Acreditamos que uma abordagem mais reflexiva com relação ao processo de avaliação possa benficiar o processo de ensino-aprendizagem, de modo que o resultado final não seja somente a aprovação em um exame de proficiência, mas a proficiência na comunicação.

\section{REFERÊNCIAS BIBLIOGRÁFICAS}

ANDRADE, Verônica Siqueira de; BARRETO, Mônica Maria Guimarães Savedra. PONTIFÍCIA UNIVERSIDADE CATÓLICA DO RIO DE JANEIRO Departamento de Letras. A competência comunicativa nas provas de redação do Deutsches 
Sprachdiplom e do Exame Nacional de Ensino Médio. 2009. Dissertação (Mestrado em Letras)-Pontifícia Universidade Católica do Rio de Janeiro, Rio de Janeiro, 2009.

ANDRÉ, Marli E. D. A. Etnografia da Prática Escolar. 14 a ed. Campinas, São Paulo: Papirus, 2008. (Série Prática Pedagógica).

ALLWRIGHT, David \& BAILEY, K. Focus on the Language Classroom: An Introduction to Classroom Research for Language Teachers. Cambridge: CUP, 1991. p 133.

CANALE, Michael. From communicative competence to communicative language pedagogy. In Richards, J.C. \& Schmidt, R.W. (eds.). Language and Communication. Essex: Longman, 1983. p. 3-27

CELCE-MURCIA, Marianne \& OLSHTAIN, Elite. Discourse and context in language teaching. Cambridge: CUP, 2000.

CHOMSKY, Noam. Aspects of theory of syntax. Cambridge: MIT Press, 1965.

CONSELHO DA EUROPA. Quadro Comum Europeu de Referência para as Línguas: aprendizagem, ensino e avaliação. Tradução de Maria Joana Pimentel do Rosário \& Nuno Verdial Soares. Porto, Portugal: Edições Asa, 2001. Disponível em <http://www.asa.pt/downloads/Quadro_Europeu_001_072.pdf > (Acessado em 16/05/2011.)

GÜNTHER, Hartmut. Pesquisa Qualitativa Versus Pesquisa Quantitativa: Esta É a Questão? In Psicologia: Teoria e Pesquisa. UNIVERSIDADE DE BRASÍLIA. Vol. 22, n. 2, p. 201-210, Maio-Ago 2006. Disponível em: <http://www.scribd.com/doc/37151315/Pesquisa-Qualitativa-Versus-PesquisaQuantitativa-Esta-E-a-Questao. htm>. Acesso em: 21 maio. 2010,14:30.

FÁVERO, Leonor Lopes. Coesão e Coerência Textuais. São Paulo: Editora Ática, 2010.

HALliDAY, M. A. K. \& HASAN, R. Cohesion in English. London: Longman, 1976.

HYMES, Dell. Models of the interaction of language and social setting. Journal of Social Issues, 1967. p. 23(2), 8-38.

On communicative competence. In J.B. Pride \& J. Holmes (Eds.), Sociolinguistics: Selected readings. Harmondsworth, England: Penguin, 1972. p. 269-293.

. The concept of communicative competence revisited. In: Pütz, Martin (Ed.) Thirty year of linguistic evolution. Philadelphia/ Amsterdam: John Benjamins, 1992. p. 31-57. 
LINCOLN, Yvonna \& GUBA, E.G. Controvérsias paradigmáticas, contradições e confluências emergentes. In Norman, Denzin K. \& LINCOLN, Yvonna S. (orgs.), O planejamento da pesquisa qualitativa. Porto Alegre: ARTMED, 2006. p.169-192.

MANUAL DO CPE - CPE: Certificate of Proficiency in English Handbook. Specifications and Sample Papers for revised examination from December 2002. University of Cambridge. Local Examinations Syndicate. UCLES 2002. EMC/287 a /2y02.

MANUAL DO CPE - CPE: Certificate of Proficiency in English- Handbook for Teachers UCLES: 2008. EMC/2318/8Y12. Disponível em <www.cambridge-efl.org> <https://www.teachers.cambridgeesol.org/ts/digitalAssets/109761_cpe_handbook.pdf> (Acessado em 08/05/2011).

RICHARDS, Jack \& RODGERS, Theodore. Approaches and Methods in Language Teaching. Cambridge University Press, 2004.

OLIVEIRA, Mariângela Rios de. Linguística Textual. In Martelotta, Mario Eduardo (org). Manual de Linguística. São Paulo: Editora Contexto. 2008: p. 193-204.

YIN, R. K. Estudo de caso: planejamento e métodos. $3^{\mathrm{a}}$ ed. Porto Alegre: Bookman, 2005.

YULE, George. Pragmatics: Oxford: Oxford University Press, 1996: p.3-8.

\section{ANEXOS}

ANEXO 1

ESQUEMA GERAL DE NOTAS

Nota: Este sistema de notas deve ser interpretado em nível de CPE. Deve ser utilizado juntamente com um esquema de notas para tarefa específica direcionado para cada questão.

\footnotetext{
Excelente realização da tarefa proposta:

- Uso sofisticado de uma extensa gama de palavras, colocações e expressões, inteiramente apropriadas à tarefa proposta

- Uso eficaz de recursos estilísticos; registro e formato inteiramente apropriado

5 - Uso impressionante de uma ampla gama de estruturas

- Muito bem organizada e coerente

- $\quad$ Erros mínimos

Impressiona o leitor e tem um efeito muito positivo Boa realização da tarefa proposta:

- Uso fluente e natural de uma ampla gama de palavras, colocações e expressões, conseguindo atender aos requisitos da tarefa proposta

- Bom uso de recursos estilísticos; registro e formato apropriado

- Uso competente de uma ampla gama de estruturas

- Bem organizada e coerente

- Bom desenvolvimento do tópico

- Pequenos erros sem importância 


\begin{tabular}{|c|c|}
\hline & Tem um efeito positivo sobre o leitor \\
\hline 3 & $\begin{array}{l}\text { Realização satisfatória da tarefa proposta } \\
\text { - Uso razoavelmente fluente e natural de uma ampla gama de palavras, colocações e expressões, adequadas } \\
\text { à tarefa proposta } \\
\text { - } \quad \text { Evidência de recursos estilísticos; registro e formato, em termos gerais, apropriado } \\
\text { - } \quad \text { Organa adequada de estruturas } \\
\text { - Abordagem do forma clara e coerente no todo adequada } \\
\text { - Alguns erros sem relevância } \\
\text { Atinge o efeito desejado sobre o leitor }\end{array}$ \\
\hline 2 & $\begin{array}{l}\text { Tentativa inadequada ao abordar a tarefa proposta } \\
\text { - Gama de palavras e expressões limitada e/ou imprecisa } \\
\text { - } \quad \text { Pouca evidência de recursos estilísticos; certo esforço em manter um registro e o formato } \\
\text { - } \text { Gama insuficiente de estruturas } \\
\text { - Desenvolvimento inadequado do tópico } \\
\text { - Vários erros, o que às vezes atrapalha a comunicação } \\
\text { Tem um efeito negativo sobre o leitor }\end{array}$ \\
\hline 1 & $\begin{array}{l}\text { Abordagem fraca da tarefa proposta: } \\
\text { - Gama de palavras e expressões extremamente limitada e imprecisa } \\
\text { - Nenhuma evidência de recursos estilísticos; pouca ou nenhuma tentativa de manter registro e formato } \\
\text { - } \text { Ausência de variedade estrutural } \\
\text { - Mal organizada, levando à incoerência } \\
\text { - Vouca relevância ao tópico e/ou curta demais } \\
\text { Possui um efeito muito negativo sobre o leitor }\end{array}$ \\
\hline 0 & $\begin{array}{l}\text { Pouco, ou nenhum, esforço em abordar a tarefa proposta: } \\
\text { - Totalmente incompreensível devido a graves erros } \\
\text { - Totalmente irrelevante } \\
\text { - Produção lingüística insuficiente para ser avaliada (menos de } 20 \% \text { do número exigido de palavras) } \\
\text { - Totalmente ilegível }\end{array}$ \\
\hline
\end{tabular}

CPE - Certificate of Proficiency in English Handbook: p 30

UCLES 2002

$\mathrm{EMC} / 287 \mathrm{a} / 2 \mathrm{y} 02$

ANEXO 2

\section{Parte 2 da prova de redação do CPE para a elaboração do gênero textual projeto (Tarefa no. 2)}

\section{Questão 2}

Você é um pesquisador e funcionário do departamento local de turismo. Seu gerente lhe pediu para redigir um projeto sobre como atrair mais visitantes, tanto do seu próprio país quanto do exterior, para sua cidade ou sua área. No seu projeto você deve incluir ideias sobre como melhorar as instalações públicas e aumentar a receita advinda do turismo.

\section{CPE - Certificate of Proficiency in English Handbook: p 33 \\ UCLES 2002}


$\mathrm{EMC} / 287 \mathrm{a} / 2 \mathrm{y} 02$

Critérios de correção específicos da parte 2 da prova de redação do CPE referente ao gênero textual proposto

\section{Conteúdo}

O projeto deve incluir:

- Como atrair mais visitantes para sua cidade ou sua área

- Como melhorar as instalações

- Como aumentar a receita advinda do turismo

\section{Variedade de estruturas léxico-gramaticais}

Linguagem para descrever, analisar, fazer recomendações e, talvez, levantar hipóteses.

\section{Adequação do registro e do formato}

Formato do projeto, provavelmente com subtópicos claros. Registro apropriado à relação comercial entre o empregado / pesquisador e o gerente que encomendou o projeto.

\section{Organização e coesão}

O projeto deve ser bem estruturado, contendo subtópicos claros. As ideias devem ser apresentadas em forma de prosa com boa organização, exibindo divisão de parágrafos e encadeamento apropriado.

\section{Leitor alvo}

Seria capaz de compreender o que o escritor está propondo

CPE - Certificate of Proficiency in English Handbook: p 36

UCLES 2002

$\mathrm{EMC} / 287 \mathrm{a} / 2 \mathrm{y} 02$ 


\section{ANEXO 3 \\ Redação corrigida pelo grupo de avaliadores de provas escritas de Cambridge (modelo de correção) Tarefa Número 2 da Parte 2 da Prova de Redação do CPE: Projeto}

A fim de promover o turismo em nosso país, eu acho que seria uma boa idéia produzir documentários especiais sobre os locais interessantes e bonitos que temos para ser visitados em nosso querido país. Isso nos permitiria recordar, (porque aprendemos na escola a respeito) os diferentes locais naturais e arqueológicos que podemos visitar.

Acho que esses programas, deveriam ser curtos porém completos. Quero dizer que eles deveriam mostrar as paisagens, deveriam nos falar algo sobre história, povo, língua, tradições, toca de moeda, hoteis onde se pode ficar; sim. Deveria nos oferecer algo semelhante ao que se pode encontrar num guia-de-turismo, mas em vez de ler, você apenas senta e assiste o que nosso país pode lhe oferecer. Dessa forma você pode atrair não só apenas turistas estrangeiros como também pode promover o turismo interno em nosso país.

A razão principal porque a maioria de nossas pessoas nem mesmo visitaram nossos principais locais turísticos é porque não têm os meios para fazê-lo, mas tenho certeza que anseiam por poder fazê-lo um dia.

Como um departamento de turismo, podemos preparar viagens curtas incluindo acomodação, bilhetes de ida e volta e guias de turismo, mas temos que ser considerado a taxa, visto que sabemos que as pessoas não podem pagar muito.

Seria interessante que promovêssemos o turismo nas escolas. Talvez dando prêmios para os melhores alunos. Esses prêmios poderiam consistir de viagens, passagens para diferentes lugares do país, de modo que eles possam visitar o que estudaram por tanto tempo na escola.

Podemos também fazer concursos sobre história com donas de casa, profisionais, (para estrangeiros ou pessoas do país) que estimulissem as pessoas a ler sobre nosso próprio país. Claro que os prêmios também seriam viagens completas para diferentes partes do nosso país.

\section{Conteúdo}

A candidata não abordou todos os aspectos do turismo mencionados na questão. Ela se concentrou na idéia de atrair mais visitantes, fazendo, no entanto, pouca referência explícita aos turistas do exterior, e não abordou adequadamente nem a melhoria das instalações nem o aumento de receita. Isso representa um esforço insuficiente de abordar a tarefa.

Variedade de estruturas léxico-gramaticais

Houve uma certa tentativa de cobrir o assunto.

\section{Correção / Acuidade da língua}

Há pouca coisa além de estruturas muito simples, ex. A razão principal porque a maioria de nós nem mesmo....; expressões pobres, ex. Como departamento de turismo... e em alguns momentos o significado não está inteiramente claro, ex. parágrafo 4.

\section{Adequação de registro e formato}

Não há esforço em apresentar esse trabalho escrito como um projeto formal, sem indicação de quem é o receptor e sem divisão clara entre as seções, com ou sem subtópicos. O registro é demasiadamente informal - o escritor simplesmente apresenta opiniões pessoais que não aparentam ter uma base forte ,ex. Eu acho.

\section{Organização e coesão}

Embora haja certa divisão em parágrafos, as sugestões não são bem organizadas.

Leitor alvo

O leitor não seria devidamente informado. 


\section{Nota 2}

CPE - Certificate of Proficiency in English Handbook: p 41

UCLES 2002

$\mathrm{EMC} / 287 \mathrm{a} / 2 \mathrm{y} 02$

\section{ANEXO 4}

Tarefa Número 2 da Parte 2 da Prova de Redação do CPE: Projeto

Texto elaborado pelo participante da pesquisa

\begin{tabular}{|c|c|}
\hline & Como atrair mais turistas \\
\hline 1 & Introdução \\
\hline 2 & O Rio de Janeiro é uma cidade maravilhosa com lindas praias e tempo quente. Além do litoral nós \\
\hline 3 & $\begin{array}{l}\text { temos até mesmo pelo menos duas cidades (Petrópolis e Teresópoli) na montanha, quase 1000m acima do nível do } \\
\text { mar }\end{array}$ \\
\hline 4 & com um tempo não tão quente. \\
\hline 5 & Tendo todas essas características favoráveis nós preparamos esta proposta com o intuito de atrair mais \\
\hline 6 & turistas para nossa região. \\
\hline 7 & Coleta de dados \\
\hline 8 & $\begin{array}{l}\text { Precisamos de alguns dados sobre os thuristas para planejar a proposta. Então, fizemos um levantamento } \\
\text { da população }\end{array}$ \\
\hline 9 & incluindo os thuristas que chegam de avião e de barco à cidade. Trezentos turistas foram escolhidos \\
\hline 10 & $\begin{array}{l}\text { aleatoriamente para fazer uma entrevista e declarar sua expectativa durante esse passeio. Eles disseram que } \\
\text { gostariam }\end{array}$ \\
\hline 11 & de viajar com segurança, ter boas acomodações e guias locais bem preparados para os eventos locais. Eles \\
\hline 12 & $\begin{array}{l}\text { gostariam também de saborear a comida local e assistir a espetáculos de música popular. Outra informação que eles } \\
\text { gostariam era }\end{array}$ \\
\hline 13 & $\begin{array}{l}\text { de ser informados sobre os consulados de seu país, considerando-se que o Rio de Janeiro é uma cidade muito grande } \\
\text { e }\end{array}$ \\
\hline 14 & importante do Brasil e deveria ter todas essas facilidades. \\
\hline 15 & O projeto \\
\hline 16 & Considerando os problemas identificados no levantamento propomos alguns procedimentos. O primeiro é \\
\hline 17 & $\begin{array}{l}\text { entrar em contato com a polícia local a fim de preparar um plano com atenção especial aos thuristas assim que eles } \\
\text { cheguem. Isso }\end{array}$ \\
\hline 18 & $\begin{array}{l}\text { requer um grupo de policial falando diferentes línguas, principalmente inglês, para dar apoio a qualquer necessidade } \\
\text { (isso }\end{array}$ \\
\hline 19 & poderia ser chamado de Polícia do Thurista). O segundo ponto foi a acomodação, que deve ser fornecida pelos \\
\hline 20 & $\begin{array}{l}\text { melhores hotéis da cidade, integrada num sistema de assistência de alta qualidade. Isso poderia incluir um show de } \\
\text { boas-vindas }\end{array}$ \\
\hline 21 & $\begin{array}{l}\text { na sua chegada o que poderia demonstrar nossa compaixão por eles. Após a chegada, os hotéis, como um todo, } \\
\text { deveriam }\end{array}$ \\
\hline 22 & forneceram transporte, de modo que eles pudessem ter facilidades nesse momento e não dependessem do sistema \\
\hline 23 & de transporte público, o qual sabemos, é deficiente. No momento do transporte para os hotéis eles \\
\hline 24 & conheceriam os guias locais especializados. Poderiam receber um folheto, feito especialmente para eles, dizendo os \\
\hline 25 & principais acontecimentos durante o mês, incluindo shows de música popular. \\
\hline 26 & clusão, achamos que essa proposta atrairá mais thuristas para a cidade considerando que foi f \\
\hline
\end{tabular}


\begin{tabular}{|l|l}
\hline 27 & Acordo com as expectativas dos thuristas. \\
\hline
\end{tabular} 